\title{
NOTE
}

\section{FORMULATION OF ALTERNATIVE MEDIA FOR FUNGAL GROWTH AND ITS APPLICATION AS AGARWOOD-INDUGING AGENT IN AQUILARIA TREES}

\author{
Rozihawati $Z^{1}$, Wan-Muhammad-Azrul WA' ${ }^{2}$, Noor-Baity ${ }^{4}$, Sheriza MR $^{1, *}$, Hazandy AH $^{5}$, \\ Mohd-Farid $\mathrm{A}^{3}$ \& Zaiton $\mathrm{S}^{1,6}$ \\ ${ }^{1}$ Institute of Tropical Forestry and Forest Products (INTROP), Universiti Putra Malaysia, 43400 UPM Serdang, \\ Malaysia \\ ${ }^{2}$ Horticulture Research Centre, Malaysian Agricultural Research and Development Institute, 43400 MARDI Serdang, \\ Malaysia \\ ${ }^{3}$ Forest Research Institute Malaysia, 52109 Kepong, Selangor, Malaysia \\ ${ }^{4}$ Faculty of Biotechnology and Biomolecular Science, Universiti Putra Malaysia, 43400 UPM Serdang, Malaysia \\ ${ }^{5}$ Faculty of Forestry and Environment, Universiti Putra Malaysia, 43400 UPM Serdang, Malaysia \\ ${ }^{6}$ School of Business and Economics, Universiti Putra Malaysia, 43400 UPM Serdang, Malaysia \\ *sheriza@upm.edu.my
}

Received February 2021; accepted May 2021

\begin{abstract}
This study investigated the growth performance of Fusarium proliferatum isolated from agarwood, on different types of plated media prepared with liquid broth extracts of locally available agricultural products. The potential of $F$. proliferatum in selected media to induce agarwood formation in Aquilaria trees was also assessed. A total of 27 media formulations were evaluated as alternative media to potato dextrose agar (PDA) for $F$. proliferatum. The effects of culture media on the diameter growth of fungal mycelium were significant $(\mathrm{F}=6.70, \mathrm{df}=26, \mathrm{p}<0.01)$. The best growth was recorded on $50 \%$ soybean followed by PDA and 70\% kidney bean with mean mycelium diameters of $7.00 \pm 0.00,6.63 \pm 0.83$ and $6.50 \pm 0.06 \mathrm{~cm}$ respectively. In the field trial, $F$. proliferatum in all three media successfully induced agarwood formation on A. malaccensis and A. crassna with significant discoloration zones compared with the uninoculated control trees $(\mathrm{p} \leq 0.05)$ after five months. Fifty percent soybean in combination with $F$. proliferatum induced the largest discoloration zone, indicating potential as a cheaper and more accessible alternative to PDA. These results suggest that the combination of a chemical inducer in the form of a liquid media formulation and a biological inducer, in this case, an endophytic fungus could successfully induce agarwood formation in Aquilaria trees.
\end{abstract}

Keywords: Fusarium proliferatum, alternative media, inoculum, plantation, agarwood

\section{INTRODUCTION}

Aquilaria spp. (family Thymelaeaceae) are known to produce agarwood or 'gaharu' in response to fungal infections and insect damage. Agarwood is a high-value non-timber product used in perfumes and pharmaceuticals. It is a valuable natural resource that can provide additional income for local communities but most of the Aquilaria species in Malaysia are now considered endangered due to overharvesting. To date, there are no obvious external signs that could be used to detect the presence of agarwood in wild Aquilaria trees. This is the reason why agarwood hunters/collectors slash the tree trunks to see if agarwood is present.
In general, only about $10 \%$ of Aquilaria trees in natural forest contain agarwood (Donovan \& Puri 2004). In Malaysia, Aquilaria malaccensis and $A$. crassna are widely planted to meet the increasing demand for agarwood and reduce harvesting pressure on dwindling natural stands (Ismail \& Mohd Zin 2010).

Inoculation of Aquilaria trees using physical, biological and chemical methods to induce agarwood production is an area of active research. An optimised media formulation and efficient inoculation technique that can produce large quantities of high quality agarwood is a most sought-after technology 
nowadays. Commercially available liquid medium formulations for agarwood induction are limited and pricey, with tree genotype and environmental factors strongly influencing agarwood induction response and quality (Naziz et al. 2019). Endophytic fungi have been employed as a biological inducer for agarwood formation with promising results (Faizal et al. 2020, Justin et al. 2020). Various species of fungi including Fusarium sp. are present in the stems of A. malaccensis (Mohamed et al. 2010, Tian et al. 2013). Fusarium sp. is a popular biological inducer for agarwood formation (Sitepu et al. 2011, Faizal et al. 2020). To ensure the effectiveness of a biological inducer, the media on which it is cultured must contain the nutrients required to support its growth and reproduction. The culture media itself can act as a chemical inducer for agarwood formation. A properly formulated inducer can induce a good amount of high quality agarwood. While recent induction approaches have largely been based on chemicals applied using custom designed delivery methods (Tan at al. 2019), biological inducers using endophytic fungi cultured in standard media such as potato dextrose agar (PDA) have also shown potential (Faizal et al. 2020). For culturing these fungi, having alternative nutrient sources based on plant or animal extracts may be useful when addressing specific requirements of intended biotechnological applications and also reducing costs in large-scale fermentation (Basu et al. 2015). Studies of the effectiveness of alternative media on the growth performance of a fungus as biological inducer of agarwood formation are lacking. Our study aimed to evaluate the growth performance of an endophytic fungus, Fusarium proliferatum on a variety of plant-based and animal-based media formulations. The potential of the fungal inoculant to induce agarwood formation on A. malaccensis and A. crassna trees in the field was assessed.

\section{MATERIALS AND METHODS}

\section{Culture media preparation}

The liquid media, which form the base for the agar culture media and which were also used for fungal inoculation, were prepared using a variety of locally sourced vegetables, grains, beef, fish and processed agricultural products that potentially support fungus growth. These main ingredients were pre-soaked with distilled water for 3 hours, boiled in $10 \% \mathrm{w} / \mathrm{v}$ water for $30 \mathrm{~min}$ then strained to collect the liquid broth extract. Large pieces, if present in the broth were ground to a paste using mortar and pestle then strained to obtain the liquid broth extract. The collected extract was used directly as liquid media at $100 \%$ concentration or diluted with distilled water to various concentrations (Table 1). The liquid media were supplemented with $5 \%(\mathrm{v} / \mathrm{v})$ local honey and $2 \%(\mathrm{v} / \mathrm{v}) \mathrm{NaCl}_{2}$. This supplemented liquid media was used together with the fungus, for inoculating Aquilaria spp. trees in the field study. For the fungal growth performance assessment in the laboratory, bacteriologicalgrade agar at $1.7 \%(\mathrm{w} / \mathrm{v})$ was added to the liquid media and plated in petri dishes.

Table 1 Media formulations plated for the fungal growth assessment

\begin{tabular}{|c|c|}
\hline Medium & Concentration $(\% \mathrm{w} / \mathrm{v})$ \\
\hline PDA & 100 \\
\hline \multirow[t]{3}{*}{ Soybean } & 50 \\
\hline & 70 \\
\hline & 100 \\
\hline \multirow[t]{3}{*}{ Kidney bean } & 50 \\
\hline & 70 \\
\hline & 100 \\
\hline \multirow[t]{3}{*}{ Mung bean } & 50 \\
\hline & 70 \\
\hline & 100 \\
\hline \multirow[t]{3}{*}{ Corn } & 5 \\
\hline & 10 \\
\hline & 15 \\
\hline \multirow[t]{2}{*}{ Wheat flour } & 10 \\
\hline & 15 \\
\hline \multirow[t]{2}{*}{ Glutinous rice flour } & 50 \\
\hline & 100 \\
\hline \multirow[t]{3}{*}{ Beef extract powder } & 50 \\
\hline & 70 \\
\hline & 100 \\
\hline \multirow[t]{2}{*}{ Bread, whole wheat } & 5 \\
\hline & 15 \\
\hline Fish, fresh mackerel & 100 \\
\hline Sweet potato & 100 \\
\hline Nestum (a commercial cereal) & 100 \\
\hline Almond & 100 \\
\hline Peanut & 100 \\
\hline
\end{tabular}




\section{Assessing the growth of $F$. proliferatum on different media}

The $F$. proliferatum isolate used in this study was obtained from the Mycology and Pathology Laboratory, Forest Biodiversity Division, Forest Research Institute Malaysia. The fungus was cultured on PDA and on the fifth day, mycelial discs measuring $0.5 \mathrm{~cm}$ across were extracted. One mycelial disc was placed at the centre of each petri dish containing the various media formulations. Commercial PDA was used as the control medium. Radial growth of the fungus was recorded daily for six days. The experiment was arranged in a completely randomised design with three replicates. Data were subjected to one-way analysis of variance (ANOVA) and mean separations were evaluated by Duncan's multiple range tests using the statistical software SPSS 17.0. The three media that supported the highest growth of $F$. proliferatum were selected as fungal inoculants for the subsequent field trial assessing their potential in inducing agarwood formation.

\section{Inoculation of field-grown Aquilaria spp.}

In the field trial, three fungal inoculants chosen for best growth performance in the laboratory experiment were tested on A. malaccensis trees at Sungai Tekala, Semenyih, Selangor and $A$. crassna trees at Jasin, Melaka. The trees were about 3 years old with a mean diameter at breast height of $12.7 \pm 1.7 \mathrm{~cm}$ and mean height of $7.5 \pm 0.8 \mathrm{~m}$. At each site, the fungal inoculant treatments were tested on 10 trees each, with 3 uninoculated trees as control, for a total of 33 trees per site. The bottle infusion method was used to administer $300 \mathrm{~mL}$ of fungal inoculant to each tree (FDPM 2012). Bottled inoculant was allowed to flow gravitationally through a plastic tube into a $1.5-2.0 \mathrm{~cm}$ hole drilled into the tree trunk. When the bottles were empty (after one or two days) the tubes were removed and each hole was plugged with a wooden stick. The inoculation was done in March 2018 and discoloration on the tree trunk indicating development of resins (agarwood) in response to wounding/infection was recorded in April, June and August 2018 using the formula:

Longitudinal discoloration length $(\mathrm{L}$, in $\mathrm{cm})$ $=\mathrm{LU} \pm \mathrm{LL}$ where, LU and LL are the upper and lower boundaries of visible discoloration. Data were subjected to one-way ANOVA, and any significant differences among treatments at 1 , 3 and 5 months after treatment were compared by Duncan's multiple range tests using the statistical software SPSS 17.0.

\section{RESULTS}

\section{Growth of $F$. proliferatum on different media}

Most of the media formulations supported the growth of $F$. proliferatum (Table 2). The effects of media on fungal mycelium diameter were significant $(\mathrm{F}=6.70, \mathrm{df}=26, \mathrm{p}<0.01)$. Of these, three media, namely, $50 \%$ soybean, PDA and $70 \%$ kidney bean showed numerically higher support for the growth of $F$. proliferatum with mean mycelium diameters of $7.00 \pm 0.00$, $6.63 \pm 0.83$ and $6.50 \pm 0.06 \mathrm{~cm}$ respectively compared to the rest of the media. Soybean has been reported as an effective medium for the growth of $F$. oxysporum (Ikechi \& Elenwo 2015), F. virguliforme and several other species of fungal pathogens (Xiang et al. 2014) as it contains carbohydrates, sugar, fibre, fat, protein, minerals and vitamins essential for the growth of fungi (Ikechi \& Elenwo 2015). Protein, especially from legumes, is a good fungal culture medium (Ravimannan et al. 2014). Carbohydrates, lipids, proteins and nucleic acids are the most important nutrients needed for microbial growth (Basu et al. 2015). These compounds are abundant in commonly available legumes (Kumar \& Xu 2017) and potato (Srivastava at al. 2011). In addition to needing organic compounds to grow, microbes also need $\mathrm{Mn}, \mathrm{Zn}, \mathrm{Co}, \mathrm{Mo}, \mathrm{Ni}$ and $\mathrm{Cu}$ for enzyme activity (Basu et al. 2015).

\section{Development of resinous zones in Aquilaria spp.}

All three fungal inoculants $50 \%$ soybean, PDA and $70 \%$ kidney bean, all inoculated with $F$. proliferatum) induced the development of significantly larger resinous zones than the control $(p<0.05$, Figure 1$)$. The resinous zone sizes for inoculated trees were double that of control three months after inoculation, and 
Table 2 Mean growth $( \pm$ SD) of Fusarium proliferatum on plated culture media prepared with liquid broth extracts of locally available agricultural products

\begin{tabular}{|c|c|c|}
\hline Ingredient & Concentration $(\% \mathrm{w} / \mathrm{v})$ & Diameter of mycelium $(\mathrm{cm})$ \\
\hline Soybean & 50 & $7.00 \pm 0.00^{\mathrm{a}}$ \\
\hline PDA & 100 & $6.63 \pm 0.68^{a}$ \\
\hline Kidney bean & 70 & $6.50 \pm 0.06^{\mathrm{a}}$ \\
\hline Mung bean & 100 & $6.00 \pm 0.58^{\mathrm{ab}}$ \\
\hline Kidney bean & 50 & $6.00 \pm 0.00^{\mathrm{ab}}$ \\
\hline Kidney bean & 100 & $5.76 \pm 0.58^{\mathrm{ab}}$ \\
\hline Bread & 15 & $5.75 \pm 0.29^{\mathrm{ab}}$ \\
\hline Beef & 50 & $5.52 \pm 0.64^{\mathrm{abc}}$ \\
\hline Fish, fresh mackerel & 100 & $5.29 \pm 0.84^{\mathrm{ab}}$ \\
\hline Soybean & 70 & $5.27 \pm 0.13^{\mathrm{abc}}$ \\
\hline Soybean & 100 & $5.25 \pm 0.43^{\mathrm{abc}}$ \\
\hline Wheat flour & 10 & $4.93 \pm 0.35^{\mathrm{abc}}$ \\
\hline Corn & 5 & $4.92 \pm 2.46^{\mathrm{abc}}$ \\
\hline Corn & 15 & $4.67 \pm 2.34^{\mathrm{abc}}$ \\
\hline Corn & 10 & $4.67 \pm 2.34^{\mathrm{abc}}$ \\
\hline Sweet potato & 100 & $4.67 \pm 0.88^{\mathrm{abc}}$ \\
\hline Nestum (a commercial cereal) & 100 & $4.42 \pm 2.21^{\mathrm{bc}}$ \\
\hline Bread & 5 & $4.12 \pm 2.06^{\mathrm{bc}}$ \\
\hline Beef & 70 & $3.72 \pm 1.87^{b c}$ \\
\hline Beef & 100 & $3.58 \pm 1.80^{\mathrm{bc}}$ \\
\hline Almond bean & 100 & $3.58 \pm 0.82^{b c}$ \\
\hline Mung bean & 70 & $3.35 \pm 0.38^{b c}$ \\
\hline Groundnut & 100 & $3.03 \pm 1.76^{\mathrm{bc}}$ \\
\hline Glutinous rice flour & 50 & $2.35 \pm 1.74^{c d}$ \\
\hline Glutinous rice flour & 100 & $2.35 \pm 1.74^{\mathrm{cd}}$ \\
\hline Wheat flour & 15 & $2.28 \pm 2.28^{\mathrm{cd}}$ \\
\hline Mung bean & 50 & $1.65 \pm 0.03^{\mathrm{d}}$ \\
\hline
\end{tabular}

*Means followed by a different letter are significantly different $(\mathrm{p}<0.05)$ 
Soybean

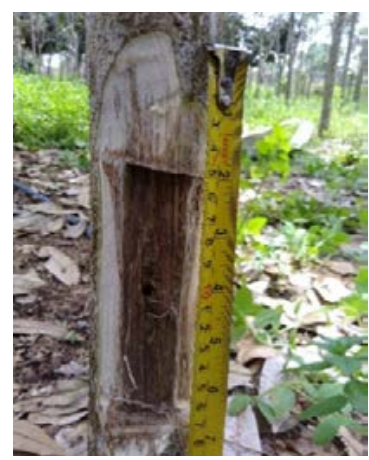

(b)

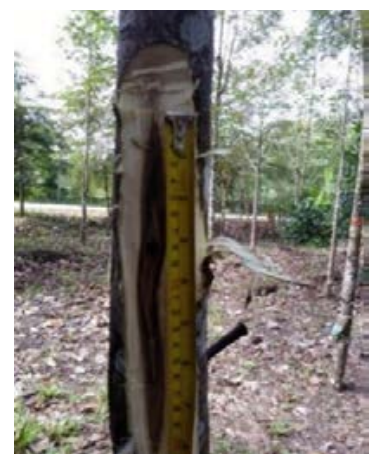

PDA
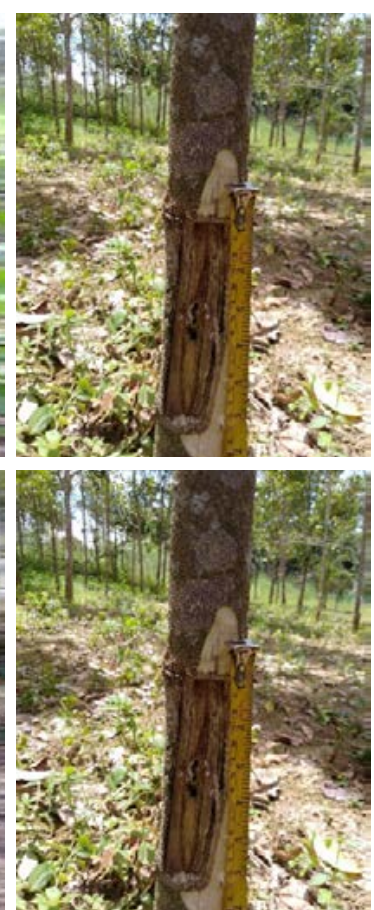

Kidney bean
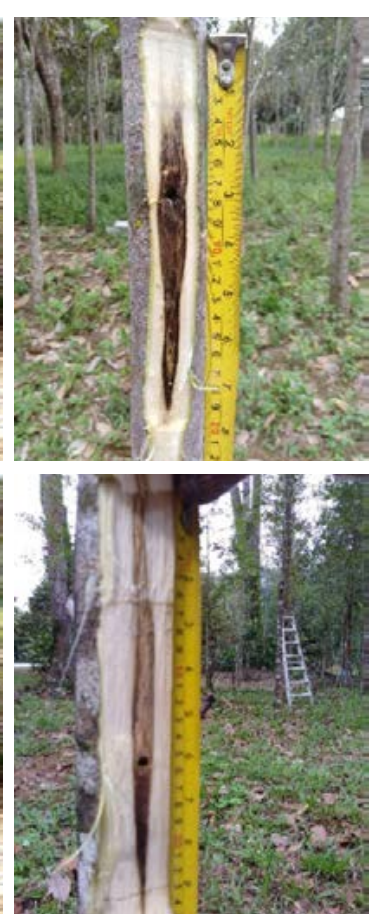

Control
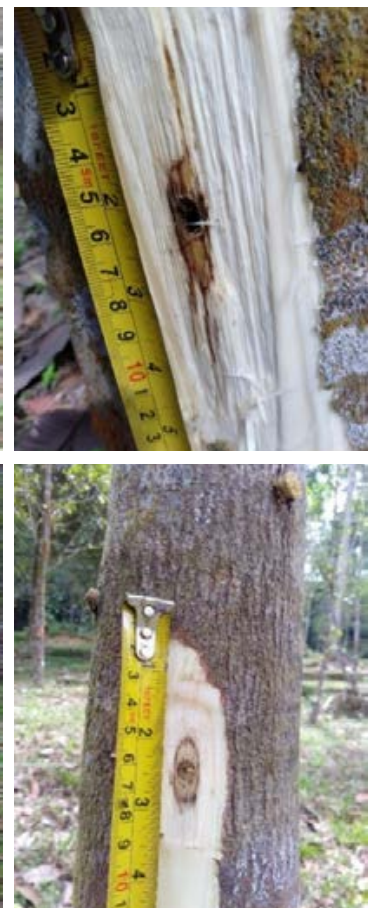

Figure 1 Discoloration zones on (a) Aquilaria crassna and (b) Aquilaria malaccensis trees 5 months after inoculation with Fusarium proliferatum in PDA, 70\% kidney bean and 50\% soybean liquid media compared with uninoculated controls

triple that by the fifth month (Figures 1 and 2). The response of both Aquilaria species to the inoculants appeared to be similar. The extension of discoloration is related to the incubation period, whereby longer incubation time produces darker agarwood formation (Mohamed et al. 2014).

The size of resinous zones formed in the inoculated trees in the field did not differ significantly between inoculant treatments. The $50 \%$ soybean and $70 \%$ kidney bean media induced comparable discoloration to standard commercial PDA indicating that alternative media formulations could be used in place of standard culture media as fungal growth promoters and as chemical inducers in the early stages of agarwood formation.

\section{ACKNOWLEDGEMENTS}

The project was supported by a grant from the Higher Institution Center of Excellence, Ministry of Higher Education of Malaysia. We would like to thank Persatuan Pengusaha Gaharu Bumiputra Malaysia for support and help. Many thanks to Ahmad-Syazwan S from FRIM for data analysis and Salim $\mathrm{S}$ for facilities at the Wood Deterioration and Protection Laboratory in Universiti Putra Malaysia.

\section{REFERENGES}

Basu S, Bose C, OJHa N et al. 2015. Evolution of bacterial and fungal growth media. Bioinformation 11: 182184. doi:10.6026/97320630011182

Donovan DG \& PURI RR. 2004. Learning from traditional knowledge of non-timber forest products: Penan Benalui and the autecology of Aquilaria in Indonesian Borneo. Ecology and Society 9: 3. https://doi.org/10.5751/ES-00678-090303

Faizal A, Azar AWP, Turjaman M \& Esyanti RR. 2020. Fusarium solani induces the formation of agarwood in Gyrinops versteegii (Gilg.) Domke branches. Symbiosis 81: 15-23. https://doi.org/10.1007/ s13199-020-00677-w

IKECHI NCG \& ELENwo EN. 2015. Evaluating some growth media for the cultivation of fungal cultures. Journal of Biology Agriculture $\mathcal{E}$ Healthcare 5: 65-74.

IsmaIl M \& MohD-ZIN J. 2010. Gaharu Komoditi Khazanah. Kayu Gaharu (M) Sdn. Bhd., Shah Alam.

FDPM (Forestry Department of Peninsular Malaysia). 2012. Panduan Penanaman Karas. FDPM, Kuala Lumpur. 


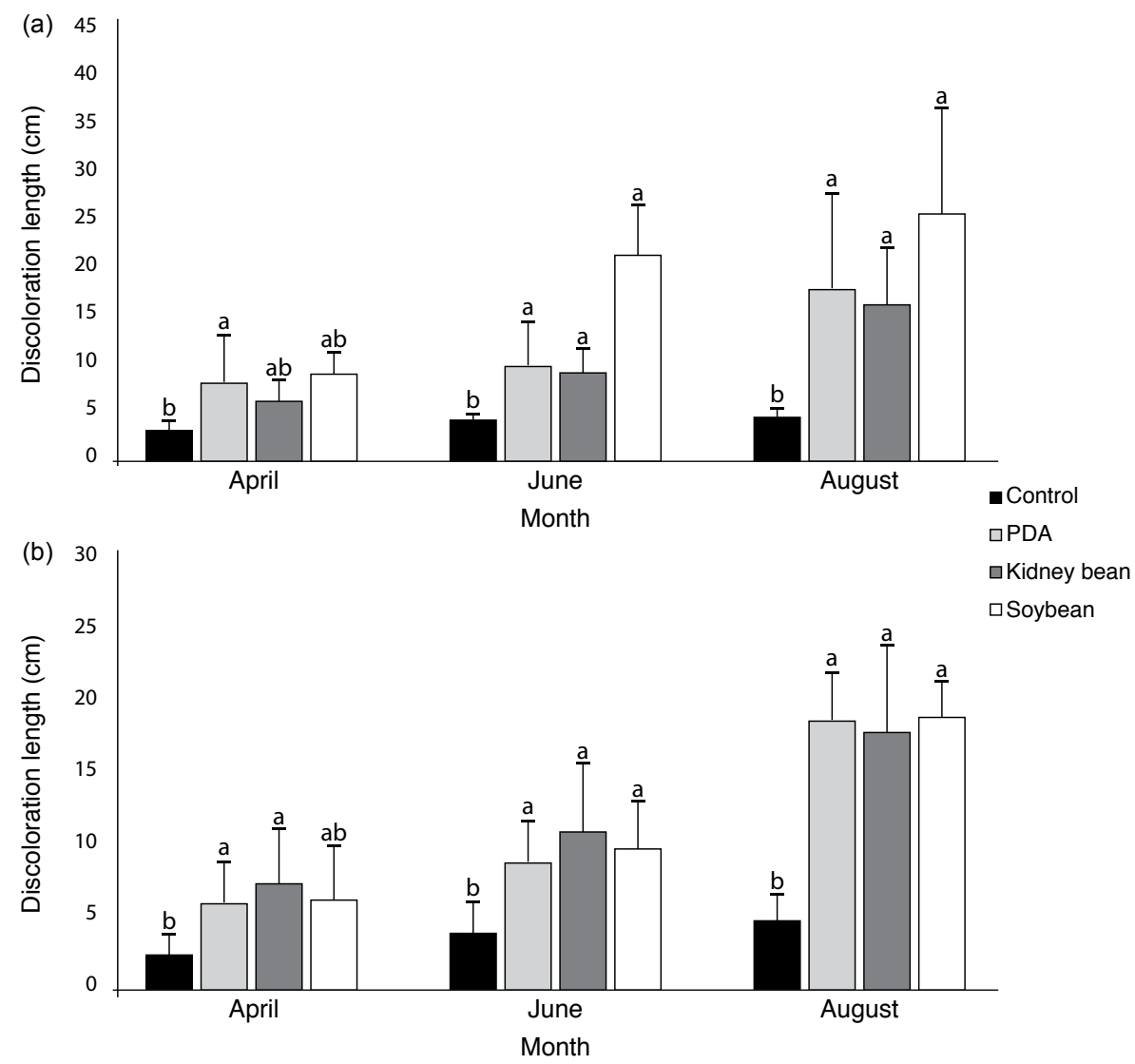

Figure 2 Mean size of discoloration zone ( \pm SD) on (a) Aquilaria crassna and (b) Aquilaria malaccensis at 1 , 3 and 5 months after inoculation with Fusarium proliferatum in PDA, 70\% kidney bean and 50\% soybean liquid media; different letters indicate significantly different means within month $(\mathrm{p}<0.05)$

Justin S, Lihan S, Elvis-Sulang MR \& Chiew TS. 2020. Formulated microbial consortium as inoculant for agarwood induction. Journal of Tropical Forest Science 32: 161-169. https://doi.org/10.26525/ jtfs32.2.161

Kumar G \& Xu B. 2017. Polyphenol-rich dry common beans (Phaseolus vulgaris L.) and their health benefits. International Journal of Molecular Science 18: 2331. https://doi.org/10.3390/ijms18112331

Mohamed R, Jong PL \& ZaLi MS. 2010. Fungal diversity in wounded stems of Aquilaria malaccensis. Fungal Diversity 43: 67-74. https://doi.org/10.1007/ s13225-010-0039-z

Mohamed R, Jong PL \& Kamziah AK. 2014. Fungal inoculation induces agarwood in young Aquilaria malaccensis trees in the nursery. Journal of Forestry Research 25: 201-204. https://doi.org/10.1007/ s11676-013-0395-0

NAZIZ PS, DAS R \& SEN S. 2019. The scent of stress: evidence from the unique fragrance of agarwood. Frontiers in Plant Science 10: 840. https://doi.org/10.3389/ fpls.2019.00840

Ravimannan N, Arulnantham R, Pathmanathan S \& Niranjan K. 2014. Alternative culture media for fungal growth using different formulation of protein sources. Annals of Biological Research 5: 36-39.

Srivastava S, Pathak N \& Srivastava P. 2011. Identification of limiting factors for the optimum growth of Fusarium oxysporum in liquid medium. Toxicology International 18: 111-116. https://doi. org/10.413/0971-6580.84262

Sitepu IR, Santoso E, Siran SA \& Turjaman M. 2011. Fragrant Wood Gaharu: When the Wild Can No Longer Provide. Ministry of Forestry of Indonesia, Bogor.

Tan C, Isa NM, Ismail I \& Zainal Z. 2019. Agarwood induction: current developments and future perspectives. Frontiers in Plant Science 10: 122. https://doi.org/10.10.3389/fpls.2019.00122

Tian JJ, Gao XX, Zhang WM, Wang L \& Qu LH. 2013. Molecular identification of endophytic fungi from Aquilaria sinensis and artificial agarwood induced by pinholes-infusion technique. African Journal of Biotechnology 12: 3115-3113.

Xiang Y, Herman T \& Hartman GL. 2014. Utilizing soybean milk to culture soybean pathogens. Advances in Microbiology 4: 126-132. https://doi. org/10.4236/aim.2014.42017 